\title{
Lesiones histopatológicas del aparato reproductor de carneros infectados experimentalmente con Brucella ovis
}

\author{
Adrián Sánchez-Orozco ${ }^{1}$, Jorge Acosta-Dibarrat ${ }^{2}$, Manuel López-Rodríguez ${ }^{1}$, Rodolfo Lucio- \\ Domínguez ${ }^{1}$, José Carlos-Bedolla ${ }^{1}$, Ruy Ortiz-Rodríguez ${ }^{1}$, Víctor Sánchez-Parra ${ }^{1}$ \\ 1 Facultad de Medicina Veterinaria y Zootecnia. Universidad Michoacana de San Nicolás de Hidalgo. Email: \\ asanchez157@outlook.com, mvzmanuellopez@hotmail.com, dr.lucio@hotmail.com, bedollajl@yahoo.com.mx, \\ ruyortiz@hotmail.com, parra1968@hotmail.com
}

2 CIESA Facultad de Medicina Veterinaria y Zootecnia. Universidad Autónoma del Estado de México. Toluca. Email: jpacosta00@hotmail.com

Brucella ovis causa epididimitis contagiosa en carneros e infertilidad, siendo la transmisión a través de mucosas. La enfermedad causa grandes pérdidas económicas. El objetivo fue describir lesiones histopatológicas en carneros infectados experimentalmente con Brucella ovis. Se usaron 18 carneros mayores a un año de edad, sanos, distribuidos aleatoriamente, en tres grupos, a saber: Grupo 1: $(n=6)$ inoculación por mucosas; Grupo 2: $(n=6)$ inoculación endovenosa y Grupo 3: $(n=6)$ control, administración de SSF (Solución Salina Fisiológica) por las mismas vías. A los 180 días pos infección, se tomaron muestras del aparato reproductivo y se procesaron para estudio histopatológico.

Las lesiones encontradas fueron edema intersticial, e infiltración perivascular de linfocitos y células plasmáticas, con metaplasia e hiperplasia del epitelio del epidídimo y formación de vesículas intraepiteliales. Los cambios muestran que el órgano más afectado en los carneros fue el epidídimo, las lesiones en su mayoría son unilaterales, también se afectaron uretra pélvica, vesícula seminal y ámpula. Se observaron células inflamatorias y granulomas en epidídimo, que concuerdan con los procesos descritos anteriormente. En testículos, al ser afectados indirectamente, hay pérdida de estructura en túbulos seminíferos.

Las lesiones, de mayor a menor grado, en infección con Brucella ovis ocurren en el epidídimo, uretra pélvica, ámpula, y testículos. El diagnóstico histopatológico es importante para conocer más esta enfermedad, dadas las implicaciones tanto económicas como en cuanto a la salud pública, por la reactividad cruzada con Brucella canis. 